\title{
O avaliar na educação física escolar
}

\author{
Evaluation in school physical education \\ Evaluación en la educación física escolar

\begin{abstract}
Rogério AlVES ANTUNES JÚNIOR ${ }^{1}$, ADMIR SOARES DE ALMEIDA JUNIOR ${ }^{2}$ UniVERSIDAde Federal de Minas Gerais, UFMG, Belo Horizonte-MG, BrasiL
\end{abstract}

\begin{abstract}
RESUMO
A avaliação na atualidade vem sofrendo questionamentos e novas possibilidades estão surgindo. Os documentos norteadores educacionais recentes apontam para uma avaliação qualitativa e processual. Na Educação Física escolar, esse movimento acontece na superação de um modelo avaliativo esportivista ou conservador, para um mais aliado às abordagens críticas. A dificuldade apresentada por muitos professores de Educação Física em relação à avaliação, reside em trabalhar com experiências corporais que não podem ser totalmente traduzidas nem pela fala, nem pela escrita. Dessa forma, é necessária a utilização de um modelo avaliativo que dialogue com a forma escolar e ao mesmo tempo abrace as especificidades da Educação Física, o que não ocorrerá sem tensionamentos.
\end{abstract}

Palavras-chave: Avaliação. Educação Física Escolar. Aprendizagem.

\begin{abstract}
Evaluation today is being questioned and new possibilities are emerging. Recent educational guidelines point to a qualitative and procedural assessment. In school Physical Education, this movement occurs in overcoming sportive or conservative evaluative model, for a critical approaches closer model. The difficulty presented by many Physical Education teachers in relation to assessment, lies in working with bodily experiences that cannot be fully translated neither by speech nor by writing. Thus, it is necessary to use an evaluative model that dialogs with the school form and at the same time embraces the specificities of Physical Education, such a model will not occur without tension.
\end{abstract}

Keywords: Evaluation. School Physical Education. Learning.

\section{RESUMEN}

La evaluación de hoy está siendo cuestionada y están surgiendo nuevas posibilidades. Las pautas educativas recientes apuntan a una evaluación cualitativa y de procedimiento. En la educación física escolar, este movimiento tiene lugar en la superación de un modelo de evaluación deportivo o conservador, para un aliado más a los enfoques críticos. La dificultad presentada por muchos maestros de Educación Física en relación con la evaluación radica en trabajar con experiencias corporales que no se pueden traducir completamente ni con el habla ni con la escritura. Por lo tanto, es necesario usar un modelo evaluativo que dialoga con la forma de la escuela y al mismo tiempo abarca los detalles de la Educación Física, que no sucederá sin tensión.

Palabras clave: Evaluación. Educación Física Escolar. Aprendizaje.

\footnotetext{
1 Mestre em Educação Física Escolar (PROEF/UFMG). E-mail: rogeriojr5@hotmail.com. ORCID: http://orcid.org/0000-0003-3588-032X.

${ }^{2}$ Professor Adjunto do Departamento de Educação Física da UFMG e do Programa de Mestrado Profissional em Educação Física em Rede Nacional (PROEF) na UFMG. E-mail: admir.almeidajunior@gmail.com. ORCID: http://orcid.org/0000-0002-7489-4161.
} 


\section{INTRODUÇÃOO}

$\mathrm{Na}$ atualidade, novas possibilidades de se projetar uma avaliação com diferentes registros vêm sendo utilizadas. Nessa perspectiva, a avaliação é mais complexa do que tomar exclusivamente o desempenho dos alunos em uma prova e considerá-los aprovados ou reprovados (DARIDO, 2012). Para Libâneo (1994), avaliação é uma tarefa complexa que não se resume à realização de provas e atribuição de notas. Dessa forma, a apreciação qualitativa dos resultados de uma avaliação fornece ao professor dados para uma reflexão sobre a sua prática docente, demonstrando em que medida suas abordagens e metodologias estão sendo eficientes nos diferentes campos de aprendizagens dos alunos.

Nas últimas décadas, na Educação Física escolar brasileira, é possível identificar um movimento que busca superar um modelo avaliativo esportivista ou conservador em que os critérios avaliativos eram o desempenho das capacidades físicas e esportivas, testes físicos, habilidades motoras, medidas antropométricas-, a partir de um modelo atrelado ao movimento renovador da década de 1980, no qual a avaliação vem sendo substituída por uma visão mais processual, abrangente e qualitativa (DARIDO, 2012).

Com essa mudança de paradigma da avaliação na educação e em especial na Educação Física escolar, surge o interesse em pesquisar, através de uma pesquisa bibliográfica, como a avaliação na Educação Física escolar vem se desenvolvendo e transformando nos últimos anos, de modo a contribuir com informações que auxiliem outros docentes a (re)significar práticas avaliativas que estejam vinculadas a especificidade da Educação Física escolar. Para Schneider e Bueno (2005), a disciplina Educação Física se diferencia dos outros componentes curriculares, pois trabalha com saberes que se organizam em uma esfera diferente. Corroborando com esse ponto, Charlot (2009) salienta que a Educação Física não é uma componente curricular escolar como as demais porque lida com uma forma de aprender que não a apropriação de enunciados. Em vez de tentar anular ou esconder essa diferença, dever-se-ia destacá-la e esclarecê-la.

Este artigo é oriundo da dissertação de mestrado (ANTUNES JÚNIOR, 2020), do programa de Mestrado Profissional em Educação Física em Rede Nacional (PROEF).

\section{DESENVOLVIMENTO}

A avaliação de aprendizagem escolar é, ou deveria ser utilizada, como um meio de se obter informações sobre os avanços e dificuldades dos discentes, sendo um procedimento contínuo de suporte para o docente e discente em suas tomadas de decisões.

Haydt (2003) considera a avaliação um processo contínuo e sistemático, não podendo ser esporádico e improvisado, tem a função de fornecer um feedback para alunos e professores, para que possam atingir os objetivos previstos.

Luckesi (1995), ao criticar o uso da avaliação como um ponto final no processo de ensino aprendizagem, realiza a seguinte analogia:

Para caracterizar essa situação - de forma até exacerbada - vamos exemplificar com a avaliação que um médico faz de seu paciente. $\mathrm{O}$ cliente de um médico - que pode ser você, posso ser eu ou tantas outras pessoas vai ao consultório sentindo dores torácicas e com febre. $\mathrm{O}$ médico faz alguns exames preliminares e constata que o sujeito está com pneumonia. Então, toma sua ficha, faz anotações sobre o nome, idade, endereço do cliente e 
acrescenta observações sobre seu estado de saúde. A seguir, despede-se do cliente, dizendo-lhe que volte quinze dias depois. O cliente foi classificado como portador de pneumonia e, a seguir, foi-lhe pedido que continuasse como estava. Certamente vai morrer. Foi classificado, mas não se tomou nenhuma decisão sobre o que fazer com ele. Vamos transpor essa situação para a escola e verifiquemos como o professor usa a avaliação. Certamente, ele tem agido da mesma forma que aquele médico. Toma o aluno, aplica-lhe um teste, corrige-o, atribui-lhe uma menção, classificando-o em péssimo (notas 0-4), em regular (notas de 5-6), em bom (notas 7-8) e excelente (notas 9-10) e registrando essa classificação no Diário de Classe. E daí para a frente deixa o aluno, sem fazer nada para que ele avance se não está bem (LUCKESI, 1995, p. 77).

Apesar dos inúmeros questionamentos, críticas e discussões, o uso predominante da avaliação escolar na atualidade, ainda se encontra em sua grande maioria no modelo conservador. Não atendendo somente a uma lógica classificatória e discriminatória, segue também uma ideologia mercadológica, positivista e neoliberal, com avaliações estandardizadas que valorizam somente os resultados mensuráveis, quantitativos e segundo seus seguidores, mais objetivos (AFONSO, 2002).

Os procedimentos avaliativos utilizados em grande parte das escolas ainda estão atrelados à transmissão e memorização dos conteúdos, sendo a avaliação um fim nela mesma, se restringindo a mensurar a quantidade de informações retidas, desvinculada do processo de ensino e de aprendizagem. É uma visão antiquada, conservadora, arcaica e ao mesmo tempo predominante. A esse modelo avaliativo, Freire (1987) denominou de "educação bancária", onde ao longo de um determinado período o educador "faz os depósitos" de conhecimento e ao final volta para "cobrá-los".

Os estudos sobre avaliação voltados para as constatações e denúncias já ofereceram sua parcela de contribuição, as pesquisas precisam ir em direção à investigação, análise e divulgação de iniciativas em avaliações comprometidas com a aprendizagem de todos os alunos, sem rótulos e classificações (BOAS, 2002 citado por SANTOS, 2005).

Analisando os últimos documentos educacionais, encontramos uma mudança em nível textual da avaliação. Na Base Nacional Comum Curricular, a avaliação é citada em uma perspectiva mais ampla, para além da mensuração, porém, sem grandes detalhamentos sobre.

Construir e aplicar procedimentos de avaliação formativa de processo ou de resultado que levem em conta os contextos e as condições de aprendizagem, tomando tais registros como referência para melhorar o desempenho da escola, dos professores e dos alunos (BRASIL, 2017, p. 17).

No Currículo Referência de Minas Gerais (2018), a avaliação também é citada em uma perspectiva mais ampla, aliada ao processo de ensino e aprendizagem, diferente da BNCC, apresenta um texto mais denso.

A avaliação deve ser vista, portanto, como um ponto de partida, de apoio, um
elemento a mais para repensar e planejar a ação pedagógica e a gestão
educacional, ancorada em objetos e expectativas que buscam ajustá-las à
aprendizagem dos estudantes. Os pontos de chegada são o direito de aprender
e o avanço na melhoria da qualidade do ensino. E para que isso ocorra é
importante que todos os profissionais envolvidos no processo educativo
compreendam os dados e informações produzidas pelas avaliações de tal
modo que, além de utilizá-los para a elaboração e implementação de ações,
desmistifiquem a ideia de que a avaliação é apenas um instrumento de 
controle, ou ainda, que a sua função é comparar escolas ou determinar a promoção ou retenção dos estudantes (MINAS GERAIS, 2018, p. 23).

Para que possamos compreender a avaliação na Educação Física nos dias de hoje, é necessário realizarmos um breve histórico das transformações e influências sofridas pela área no contexto brasileiro ao longo dos anos. O processo avaliativo na Educação Física escolar sempre esteve subordinado ao pensamento político, econômico e social da época.

Desde a década de 1851, com a lei $\mathrm{n}^{\circ}$ 630, conhecida como Reforma Couto Ferraz, tornou obrigatória Educação Física nas escolas do município da Corte. Em 1876, o Decreto-Lei $n^{\circ} 6370$ tornou o ensino mais sistemático a partir da ginástica para escolas primárias, emergindo das próprias transformações da sociedade, tendo aspectos, higienista, militarista, popular e pedagógico. As práticas avaliativas na educação em geral e na Educação Física eram baseadas na cultura do exame, visando impor medo, como forma de controle, seleção técnica e social (PONTES JUNIOR, 2017).

Nas décadas de 1900 a 1930, servindo como instrumento de controle médicosanitarista, a Educação Física tinha a premissa da eugenização e desenvolvimento de hábitos de higiene e saúde, a avaliação era direcionada nesse sentido, se limitando as atitudes e hábitos de higiene (PONTES JUNIOR, 2017).

Nas décadas de 1930 e 1940, as instituições militares, influenciadas pelo positivismo, começaram a pregar a educação do físico, com o objetivo de criar indivíduos fortes e saudáveis, que pudessem defender a pátria e seus ideais (BRASIL, 1997).

No início do século XX, a Educação Física, com o nome de ginástica, foi incluída nos currículos dos Estados da Bahia, Ceará, Distrito Federal, Minas Gerais, Pernambuco e São Paulo. Com a educação brasileira sofrendo forte influência do movimento escolanovista, a Educação Física, baseada nos métodos europeus, o sueco, o alemão e posteriormente o francês, que se firmavam em princípios biológicos, teria como função o desenvolvimento integral do ser humano (BRASIL, 1997).

No método francês, a avaliação era pautada em dados anátomo-fisiológicos com base em medidas biométricas, fichas médicas e testes padronizados (MAUAD, 2003).

$\mathrm{Na}$ década de 1930, no Brasil, em um contexto histórico e político mundial, com a ascensão das ideologias nazistas e fascistas, as ideias de eugenização ganham força novamente na Educação Física. O exército passa a ser a instituição a influenciar e comandar a Educação Física, que agora possui objetivos patrióticos e de preparação prémilitar (BRASIL, 1997). A avaliação na tendência militarista pautava-se nas capacidades físicas, com testes de força, velocidade, flexibilidade, destreza, agilidade e resistência cardiorrespiratória, com o objetivo de selecionar os mais aptos para a defesa da pátria. O critério para aprovação ou reprovação, eram as capacidades físicas (PONTES JUNIOR, 2017).

A avaliação em Educação Física escolar, até os anos 1960, utilizava os testes de "Suficiência ou eficiência física". Os professores, em sua grande maioria, desconheciam a validade desses testes, outros desconheciam as limitações de cada teste e até mesmo as limitações do próprio aluno em realizá-lo. Em cada teste, o aluno precisava executar um determinado número de repetições, dentro de um determinado tempo. Existiam provas diferentes para o sexo masculino e feminino (OHLWEILER, 1993).

Esse modelo de avaliação foi aos poucos sendo substituída por testes de atividades físicas e esportivas, com o objetivo de fornecer informações sobre as capacidades físicas e habilidades esportivas dos alunos (OHLWEILER, 1993).

Com a Lei de Diretrizes e Bases da Educação, de 1961, inicia-se o processo de esportivização da Educação Física escolar com o Método Desportivo Generalizado, 
rompendo com a tradição dos métodos europeus (BRASIL, 1997). Na tendência esportivista, as avaliações eram baseadas na medição, desempenho das capacidades físicas, das habilidades motoras e em alguns casos o uso de medidas antropométricas (DARIDO, 2012). Buscando o aperfeiçoamento das técnicas e táticas esportivas, aumentando a competitividade entre os alunos e mudando a relação de professor-aluno para técnico-atleta (PONTES JUNIOR, 2017).

$\mathrm{Na}$ década de 1980, os efeitos desse modelo começaram a ser contestados, o Brasil não se tornou uma potência olímpica e a competição esportiva de elite não alavancou. Foi o início de uma profunda crise de identidade da Educação Física escolar que estava voltada principalmente para a escolaridade de quinta a oitava série do primeiro grau, e passa a dar prioridade a primeira a quarta série e também à pré-escola. O objetivo e a avaliação passaram a ser o desenvolvimento psicomotor do aluno, propondo-se retirar da escola a função de promover os esportes de alto rendimento (BRASIL, 1998).

Ocorreram vários debates e novas formas de pensar da Educação Física escolar foram surgindo, influenciadas pelas recém-criadas organizações da sociedade civil, a criação dos primeiros cursos de pós-graduação em Educação Física, o retorno de professores doutorados que estavam fora do Brasil, as publicações de um número maior de livros e revistas, além do aumento do número de congressos e outros eventos dessa natureza (BRASIL, 1998). Apesar dos debates e das mudanças de discurso, o modelo esportivista continuou a influenciar muitos professores em sua prática (DARIDO; SOUZA JUNIOR, 2007), e ainda influencia nos dias de hoje.

Com a promulgação da Lei de Diretrizes e Bases da Educação Nacional (LDB n ${ }^{\circ}$ 9394/96), a Educação Física garantiu a sua condição de componente curricular na Educação Básica. Em 1997, os Parâmetros Curriculares Nacionais, inspirados nos princípios do movimento renovador, consolidou a cultura corporal de movimento como objeto de estudo da Educação Física escolar (GONZÁLEZ et al., 2013).

A ruptura do "exercitar para", obrigou a Educação Física a reinventar o seu espaço na escola, assumindo o posto de componente curricular, que trata de um conhecimento específico. Porém, essa "nova Educação Física" não acontece de forma hegemônica dentro das escolas. Dessa forma, para González e Fensterseifer (2009), a Educação Física se encontra "entre o não mais e o ainda não", uma prática docente na qual não se acredita mais, e outra que ainda se tem dificuldades de pensar e desenvolver.

Dentre as abordagens do movimento renovador, abordaremos a concepção de avaliação e os métodos avaliativos da abordagem Crítico Superadora. A abordagem faz uma crítica aos métodos conservadores de avaliação na Educação Física (avaliação quantitativa, biológica, classificatória, discriminatória e mecânico-burocrática). É necessário considerar que a avaliação do processo de ensino e de aprendizagem está diretamente relacionada ao projeto pedagógico da escola. Servindo como referência na busca de elementos para analisar a aproximação ou o distanciamento do mesmo (SOARES et al., 1992).

Segundo os autores da abordagem crítico superadora a avaliação deve considerar a observação, análise e conceituação de elementos que compõe a totalidade da conduta humana. Dessa forma, a avaliação na abordagem Crítico Superadora rompe com o modelo conservador, aponta para uma avaliação mais qualitativa, contínua e que esteja relacionada ao projeto político pedagógico.

Mesmo com ascensão da abordagem crítico superadora, muitos professores ainda permaneciam em uma crise de identidade profissional. A crítica ao esporte de rendimento criou um vazio para muitos professores, que tiveram sua formação e sua 
prática alicerçada em uma perspectiva esportivista. Alguns professores se aproximaram de outras abordagens ou permaneceram na esportivista, outros se encontravam sem norte.

Nesse vazio que muitos professores se encontravam, foi se desenvolvendo um "modelo" (que não foi e nem é defendido por estudiosos e acadêmicos) de Educação Física no qual os alunos decidem o que vão fazer na aula, escolhendo o jogo e a forma como irão praticá-lo, o professor agora se restringe a oferecer uma bola e marcar o tempo (DARIDO; SOUZA JUNIOR, 2007).

\begin{abstract}
Não há estatísticas sobre o assunto, mas, nas descrições das pessoas envolvidas no universo escolar, esse fenômeno parece bastante comum. Aulas que parecem não ser aulas, no momento em que nesses espaços não há pessoas empenhadas em ensinar a seus alunos, senão crianças e jovens que apenas "jogam" ou passam o tempo numa conversa amena, sob olhar de um adulto que controla o tempo e o material esportivo (GONZÁLEZ; FENSTERSEIFER, 2006, p. 2-3).
\end{abstract}

Após quase quatro décadas das primeiras propostas renovadoras, ainda se faz presente a lógica que sustentou o trabalho docente em Educação Física por quase um século. O contexto escolar revela um caráter ainda conservador na Educação Física, ou o que é ainda pior, o abandono do trabalho docente (GONZÁLEZ et al., 2013).

Nos dias de hoje, a avaliação mais utilizada na Educação Física escolar é a nãoavaliação. O professor não utiliza instrumentos avaliativos, para cumprir a burocracia do preenchimento das notas e resultados, utiliza critérios subjetivos, onde nem mesmo o aluno toma conhecimento de como está sendo avaliado (SILVA et al., 2018).

Eu não me recordo de alguma disciplina da graduação que me disse como avaliar nas aulas de Educação Física. Passava muito pela observação. E sem nenhum tipo de registro [...] uma observação assim no sentido de participação. $\mathrm{O}$ aluno participou, ele recebe uma nota boa, ele não jogou, ele não participou, ele não recebe uma nota boa (OLIVEIRA, 2019, p. 79).

$\mathrm{Na}$ avaliação em Educação Física, na atualidade, não predominam mais os critérios da abordagem do esporte, porém, não atingiram ainda em sua totalidade, as abordagens críticas (SILVA et al., 2018), apesar da contribuição da autora e seus colaboradores, não podemos desconsiderar que existem diversas realidades escolares. Dessa forma, encontramos no cotidiano das escolas uma variedade enorme de modelos avaliativos. Tendo como um dos critérios a participação do aluno nas aulas, não se importando se acontecerá aprendizagem ou não. No caso, podemos dizer que não existe avaliação, e sim um critério para o preenchimento burocrático das notas.

Em contrapartida, outros professores ao buscar legitimar a Educação Física na escola, e fugirem da imagem de abandono do trabalho docente na avaliação, buscam seguir os demais componentes curriculares, utilizam uma avaliação no modelo conservador, com seus códigos e julgamentos, desconsiderando as singularidades da área. Schneider e Bueno (2005) e Charlot (2009), nos apontam para uma visão da especificidade da Educação Física escolar.

Assumir o status de disciplina singular, que trata de um outro rol de conhecimentos por meio de um outro conjunto de procedimentos, ou buscar assemelhar-se às outras disciplinas escolares por meio da adoção dos mesmos procedimentos de registro? Mas haveria que se perguntar: o registro dos saberes compartilhados por essa disciplina seria capaz de integrar a Educação Física à cultura escrita? A adoção desse procedimento seria capaz de garantir 
a sua relevância institucional? Acreditamos que essa não seja a melhor saída, uma vez que, mesmo que a cultura escrita seja a "língua da escola", o fato de possuir registros acessíveis não garantiria a sua relevância institucional, nem sua integração a esse universo de saberes intelectualizados, pois os saberes com os quais lida são, de certa forma, diferentes dos tematizados/ compartilhados pelas demais disciplinas escolares (SCHNEIDER; BUENO, 2005, p. 42).

[...] a Educação Física não é uma disciplina escolar "como as demais". E acrescento: felizmente. Não é igual às demais porque lida com uma forma do aprender outra que não a apropriação de saberes-enunciados. Em vez de tentar anular ou esconder essa diferença, dever-se-ia destacá-la e esclarecê-la. $\mathrm{O}$ fato de que é uma disciplina diferente não significa que tem menos legitimidade do que as demais disciplinas. Por que a Educação Física tende a ser desvalorizada nas escolas? Porque os professores das outras disciplinas restringem o saber ao que pode ser enunciado através da linguagem e, portanto, não consideram a Educação Física como uma disciplina escolar de parte inteira. Não é culpa deles: além de ensinarem matérias constituídas por conjuntos de enunciados, eles são vítimas da representação social dominante do que é aprender e saber, representação que expressa relações sociais de dominação. Em vez de se esforçar para aparentar-se normal, conforme a norma dominante de legitimidade escolar, a Educação Física deveria, a meu ver, legitimar-se por referência a outra norma, a outra figura do aprender (CHARLOT, 2009, p. 243).

Percebemos que a avaliação em Educação Física se apresenta nas escolas como um grande mosaico com relação ao uso de instrumentos e critérios (SILVA et al., 2018). Em meio a esses vórtices de ideias, temos de ter em mente a função primordial da avaliação: ajudar o aluno em seu processo de ensino-aprendizagem. E nesse caminho na busca de como otimizar nossos processos avaliativos, tomemos como base Hoffmann (2009), onde ela nos diz que as certezas são mais perigosas do que as incertezas no sistema de avaliação.

Quando se pensa em avaliação e realiza-se uma pesquisa de avaliação em Educação Física, não se pode desconsiderar a forma escolar, que tem como uma de suas características a "linguagem escrita". Dessa forma, aparece a contradição em se pesquisar a avaliação em um componente curricular que possui experiências que não podem ser traduzidas para a linguagem escrita. Talvez, essa seja a dificuldade apresentada por muitos professores de Educação Física com relação à avaliação, trabalhar com experiências corporais que não podem ser totalmente traduzidas nem pela fala, nem pela escrita.

Segundo Almeida Junior (2011), para um modelo de processo de ensino, de aprendizagem e de avaliação em Educação Física alinhado as suas especificidades é necessário apostar em uma perspectiva de ensino de Educação Física pautada numa relação dialógica, que compreenda os diferentes significados produzidos pelos estudantes, com relação ao lugar da Educação Física na escola. O autor discorre sobre a potencialidade dos diferentes registros produzidos pelos alunos nas aulas de Educação Física, destacando a produção de imagens fotográficas como outra possibilidade de evidenciar o processo de ensino e de aprendizagem na Educação Física.

\section{CONSIDERAÇÕES FINAIS}

Os modelos e processos avaliativos vêm sendo questionados na atualidade, mas apesar dos esforços estamos mais próximos dos modelos avaliativos de séculos atrás. 
Apesar dos recentes documentos se referindo a uma avaliação mais qualitativa e processual, posteriormente esses mesmos órgãos que lançam os documentos, aplicam uma avaliação quantitativa e classificatória.

A avaliação na Educação Física escolar esteve ao longo da história subordinada ao pensamento político, econômico e social da época, inicialmente no período higienista, como uma avaliação baseada nas atitudes e hábitos de higiene. Nos métodos europeus, no geral apresentavam um sistema avaliativo baseado em dados anátomo-fisiológicos com base em medidas biométricas. No período militarista, temos um modelo avaliativo pautado nas capacidades físicas, com testes de força, velocidade, flexibilidade, destreza, agilidade e resistência cardiorrespiratória. No período esportivista, as capacidades físicas e habilidades esportivas eram os parâmetros avaliados. Com o movimento renovador da década de 1980, surge a abordagem critico superadora contraria aos modelos avaliativos anteriores e apontando para uma avaliação mais qualitativa e processual. $\mathrm{Na}$ atualidade, encontramos na Educação Física escolar uma variedade de práticas avaliativas, algumas preocupas com o preenchimento burocrático, outras alinhadas com a forma escolar, na busca de uma legitimidade e existem também aquelas que procuram dialogar com a forma escolar e que ao mesmo tempo leva em consideração as especificidades da Educação Física.

Para Matsumoto (2014), a Educação Física tem uma relação com o espaço escolar diferenciada, fisicamente mais aberta ao exterior da escola, o professor de Educação Física vive a escola por dentro e também de uma região entre o dentro e o fora separada da rua por um muro. Além do espaço físico, tem-se um ponto de vista diferenciado como área do conhecimento, compomos uma "região" entre o dentro e o fora também do conhecimento escolar. Pois, mesmo legitimada pela lei como componente curricular, a Educação Física, assim como outros componentes curriculares, continua na "periferia do currículo".

O desafio reside em encontrar formas de avaliação que dialoguem com a forma conservadora (escrita), que abrace as especificidades da Educação Física e leve em consideração a enorme variedade de realidades na cultura escolar. Não se tem a pretensão aqui de se sugerir um guia de avaliação em Educação Física, somente o objetivo de criar uma reflexão para a avaliação no componente curricular que possa abrir uma janela de possibilidades.

A utilização de um modelo avaliativo em Educação Física, respeitando suas especificidades, não acontecerá sem tensionamentos, pois, esse modelo, extrapola a forma escolar, acionando as luzes vermelhas das instituições de ensino.

\section{REFERÊNCIAS}

AFONSO, A. J. Escola pública, comunidade e avaliação: Resgatando a avaliação formativa como instrumento de emancipação. In: ESTEBAN, M. T. (org.). Avaliação: uma prática em busca de novos sentidos. 4. ed. Rio de Janeiro: DP\&A, 2002. p. 83-99.

ALMEIDA JÚNIOR, A. S. Foto e grafias: narrativas e saberes de professores/as de educação física. 2011. 493 p. Tese (Doutorado em Educação) - Faculdade de Educação, Universidade Estadual de Campinas, Campinas, 2011.

ANTUNES JÚNIOR, R. A. Percepções e sentimentos de estudantes na avaliação em educação física escolar. 2020. 136 f. Dissertação (Mestrado em Educação Física) - Escola de Educação Física, Fisioterapia e Terapia Ocupacional, Universidade Federal de Minas Gerais, Belo Horizonte, 2020.

BRASIL. Base nacional comum curricular: educação infantil e ensino fundamental. Brasília: MEC/Secretaria de Educação Básica, 2017. 
BRASIL. Secretaria de Educação Fundamental. Parâmetros curriculares nacionais: educação física. Brasília: MEC/SEF, 1998.

BRASIL. Secretaria de Educação Fundamental. Parâmetros curriculares nacionais: educação física. Brasília: MEC/SEF, 1997.

CHARLOT, B. Ensinar a educação física ou ajudar o aluno a aprender o seu corpo-sujeito? In: DANTAS JÚNIOR, H. S.; KUHN, R.; RIBEIRO, S. D. D. Educação física, esporte e sociedade: temas emergentes. São Cristóvão: Editora da UFS, 2009. p. 231-246. v. 3.

DARIDO, S. C. A avaliação da educação física na escola. In: UNIVERSIDADE ESTADUAL PAULISTA. Prograd. Caderno de formação: formação de professores didática geral. São Paulo: Cultura Acadêmica, 2012. p. 127-140. v. 16.

DARIDO, S. C; SOUZA JÚNIOR, O. M. Para ensinar educação física: possibilidades de intervenção. Campinas: Papirus, 2007.

FREIRE, P. Pedagogia do oprimido. 17. ed. Rio de Janeiro: Paz e Terra, 1987.

GONZÁLEZ, F. J.; FENSTERSEIFER, P. E. Entre o "não mais" e o “ainda não": pensando saídas do não lugar da EF escolar I. Cadernos de Formação RBCE, v. 1, p. 9-24, set. 2009.

GONZÁLEZ, F. J.; FENSTERSEIFER, P. E.; RISTOW, W. R.; GLITZ, A. P. O abandono do trabalho docente em aulas de educação física: a invisibilidade do conhecimento disciplinar. Educación Física y Ciencia, v. 15, n. 2, 2013.

GONZÁLEZ, F. J; FENSTERSEIFER, P. E. Educação Física e cultura escolar: critérios para identificação do abandono do trabalho docente. In: CONGRESSO SUL BRASILEIRO DE CIÊNCIAS DO ESPORTE, 3., 2006, Santa Maria. Anais [...] Santa Maria, 2006.

HAYDT, R. C. C. Curso de didática geral. São Paulo: Ática, 2003.

HOFFMAnN, J. M. L. Avaliação: mito e desafio: uma perspectiva construtivista. Porto Alegre: Mediação, 2009.

LIBÂNEO, J. C. Didática. 13 ed. São Paulo: Cortez, 1994.

LUCKESI, C. C. Avaliação da aprendizagem escolar: estudos e proposições. 3. ed. São Paulo: Cortez, 1995.

MATSUMOTO, M. H. Avaliação e educação física escolar: práticas cotidianas de professores da rede pública do estado de São Paulo. 2014. 258 p. Tese (Doutorado em Educação) - Faculdade de Educação, Universidade Estadual de Campinas, Campinas, 2014.

MAUAD, J. M. Avaliação em educação física escolar: relato de uma experiência. 2003. 98 f. Dissertação (Mestrado em Educação Física) - Faculdade de Educação Física, Universidade Estadual de Campinas, Campinas, 2003.

MINAS GERAIS. Currículo Referência de Minas Gerais. Secretaria de Estado de Educação de Minas Gerais - SEE/MG, 2018.

OHLWEILER, Z. N. C. Avaliação da aprendizagem na educação física: uma prática possível. Santa Cruz do Sul: Livraria e Editora da UNISC, 1993.

OLIVEIRA, J. L. Avaliação nas aulas de educação física: Práticas e produções cotidianas na escola. 2019. 66 f. Produto Técnico (Mestrado em Educação) - Faculdade de Educação, Universidade Federal de Minas Gerais, Belo Horizonte, 2019. 
PONTES JUNIOR, J. A. Avaliação em educação física escolar. Fortaleza: EdUECE, 2017. Disponível em: https://www.researchgate.net/publication/322406170_Avaliacao_em_Educacao_Fisica_Escolar. Acesso em: 03 jan. 2019.

SANTOS, W. Avaliação na educação física escolar: do mergulho à intervenção. 2005. $241 \mathrm{f}$. Dissertação (Mestrado em Educação) - Faculdade de Educação, Universidade Federal de Minas Gerais, Belo Horizonte, 2005.

SCHNEIDER, O.; BUENO, J. G. A relação dos alunos com o saber compartilhado nas aulas de educação física. Movimento: Revista da Escola de Educação Física, Porto Alegre, v. 11, n. 1, p. 23-46, jan./abr. 2005.

SILVA, V. T.; SILVA, B. A. T.; MELO, L. F.; NISTA-PICCOLO, V. L. A avaliação na educação física escolar: um estudo com professores da rede pública do estado de São Paulo. Conexões: Educação Física, Esporte e Saúde, v. 16, n. 1, p. 2-16, maio 2018.

SOARES, C. L.; TAFFAREL, C. N. Z.; VARJAL, E.; CASTELLANI FILHO, L.; ESCOBAR, M. O., BRACHT, V. Metodologia do ensino da educação física. São Paulo: Cortez, 1992.

Recebido em: 14 jul. 2020.

Aprovado em: 31 ago. 2020. 